\title{
What Authors Think about Hypertext Authoring
}

\author{
Sofia Kitromili $†$ \\ ECS / Web Science \\ University of Southampton \\ Southampton, UK \\ s.kitromili@soton.ac.uk
}

\author{
James Jordan \\ English \\ University of Southampton \\ Southampton, UK \\ jaj1@soton.ac.uk
}

\author{
David E. Millard \\ Electronics and Computer Science \\ University of Southampton \\ Southampton, UK \\ dem@soton.ac.uk
}

\begin{abstract}
Despite significant research into authoring tools for interactive narratives and a number of established authoring platforms, there is still a lack of understanding around the authoring process itself, and the challenges that authors face when writing hypertext and other forms of interactive narratives. This has led to a monolithic view of authoring, which has hindered tool design, resulting in tools that can lack focus, or ignore important parts of the creative process. In order to understand how authors practise writing, we conducted semi-structured interviews with 20 interactive narrative authors. Using a qualitative analysis, we coded their comments to identify both processes and challenges, and then mapped these against each other in order to understand where issues occurred during the authoring process. In our previous work we were able to gather together a set of authoring steps that were relevant to interactive narratives through a review of the academic literature. Those steps were: Training/Support, Planning, Visualising/Structuring, Writing, Editing, and Compiling/Testing. In this work we discovered two additional authoring steps, Ideation and Publishing that had not been previously identified in our reviews of the academic literature - as these are practical concerns of authors that are invisible to researchers. For challenges we identified 18 codes under 5 themes, falling into 3 phases of development: Preproduction, where issues fall under User/Tool Misalignment and Documentation; Production, adding issues under Complexity and Programming Environment; and Post-production, replacing previous issues with longer term issues related to the narrative's Lifecycle. Our work shows that the authoring problem goes beyond the technical difficulties of using a system, rather it is rooted in the common misalignment between the authors' expectations and the tools capabilities, the fundamental tension between expressivity and complexity, and the invisibility of the
\end{abstract}

Permission to make digital or hard copies of all or part of this work for personal or classroom use is granted without fee provided that copies are not made or distributed for profit or commercial advantage and that copies bear this notice and the full citation on the first page. Copyrights for components of this work owned by others than ACM must be honored. Abstracting with credit is permitted. To copy otherwise, or republish, to post on servers or to redistribute to lists, requires prior specific permission and/or a fee. Request permissions from Permissions@acm.org. $H T^{\prime} 20$, July 13-15, 2020, Virtual Event, USA

(C) 2020 Association for Computing Machinery.

ACM ISBN 978-1-4503-7098-1/20/07 ...\$15.00

https://doi.org/10.1145/3372923.3404798 edges of the process to researchers and tool builders. Our work suggests that a less monolithic view of authoring would allow designers to create more focused tools and address issues specifically at the places in which they occur.

\section{CCS CONCEPTS}

- Human-centred computing Interaction design Systems and tools for interaction design

\section{KEYWORDS}

Hypertext fiction, Interactive fiction, Authoring, Authors, Authoring tools, Digital interactive storytelling, Digital interactive narratives

\section{ACM Reference format:}

Sofia Kitromili, James Jordan and David E. Millard. 2020. What Authors Think about Hypertext Authoring. In Proceedings of the 31st ACM Conference on Hypertext and Social Media (HT'20), July 13-15, Virtual Event, Florida, Orlando, USA. ACM, New York, NY, USA, 9 pages. https://doi.org/10.1145/3372923.3404798

\section{Introduction}

Authoring a story, even in its simplest traditional form, can be difficult. Both the mind of an author and the narrative itself go through several iterations and amendments to create a complete piece of work that will ideally satisfy an audience [1]. When we move this process to a digital interactive form it becomes more complicated. The author is responsible for a more chaotic line of thinking, framing a story in a non-linear non-sequential format (what Murray [2] calls 'multiform'). The author also transfers some of their control to the reader [3], as interaction gives them the power to steer the narrative as they wish. If the author offers multiple plots, then the reader will have the option to follow the one closer to their preferences. If the author offers multiple endings, then the reader will reach the ending that was stirred by their choices. Authoring becomes a task of meticulous planning, of anticipating user intent and computing several different outcomes [4], and all of these possibilities must be planned, designed and developed during the authoring process.

Because hypertext and other interactive stories are digital artefacts, the authoring process necessitates digital authoring tools. Such tools are widely available, and range from the 
academic (such as StoryPlaces [5] or ASAPS [6]) to mainstream tools used by a broad community (such as Twine1 or Inform 72). Despite the proliferation of tools, authoring with them is still identified as a very difficult task $[7,8]$. However, there is a lack of understanding as to exactly why it is difficult. This is partially because authoring has been perceived as a monolithic activity, which encourages broad brush conclusions (such as blaming overall complexity or scope [9-15]). In this paper we take a more nuanced view, and look in detail at where and why issues occur.

In previous work we deconstructed the authoring process into its constituent parts [16] enabling us now to conduct a series of qualitative author interviews, and then inductively code and map them to the specific authoring processes that were identified. Our aim was to hear from Authors about the barriers they face and issues that most frustrate them, and locate where in the process those issues occur in order to help future tool builders mitigate and overcome the most common problems.

The paper is structured as follows: Section 2 defines what we mean by hypertext authoring, and gives an overview of related work in authoring tool design, as well as recapping our prior analysis of the authoring process. Section 3 presents the methodology for our qualitative interviews, and Section 4 gives an overview of the emergent codes and themes. Section 5 then presents an analysis of the key issues we identified and maps them against the existing process model. Finally, Section 6 concludes the paper, summarises our key findings and their limitations, and suggests directions for future work.

\section{Background}

The idea of interactive narratives can be dated as far back as the 1930s with a book by Doris Webster and Mary Hopkins [17] in which the reader makes choices that define the lives of the characters. This idea was popularised by the 'Choose Your Own Adventure' story books of the 1970s, a series of books for children that allowed them to make their own choices and determine outcomes [18]. Digital interactive stories emerged around the same time in the form of text adventures [19] such as Zork3. The simple interfaces and graphics of these early narrative games hid complicated computational structure and behaviour that at the time required significant coding skills to build. This restricted the people who were able to create interactive stories. In the 1980s that changed when hypertext tools started to be available to a wide audience of fiction writers, most prominently StorySpace4, which was the platform used for many of the key hypertext works of the time [20]. A generic term for all this activity, covering a wide variety of interactive narrative, was given by Aarseth who described it 'ergodic literature' [21] literally stories that require work (or at least non-trivial effort) to read. In this paper when we use the term 'hypertext' we mean it in this broad and inclusive sense.
Shibolet et al. [22] presented a 2018 review of interactive digital narrative authoring tools, identifying 183 authoring tools that met their criteria in that they provided an independent and comprehensive workspace, simplified the authoring process (i.e. is not a general purpose programming system), and have been actively used by a community of practice. There is clearly no shortage of tools. However, as with every interaction between human and computer there lies a technical barrier, particularly for those with non-technical backgrounds [7].

Authoring tools were created to make it possible for a wide range of people to use them (hence Shibolet et al.'s [22] simplification criteria), but how well do we really understand the process people are going through when writing? The people behind the development of tools are mostly concerned with the evaluation of how their tools work [23] often in the specific tasks they were designed for, and not so much concerned with how well the tool aligns with the purposes and writing methods of authors. Without denying the intrinsic value of the tools, it is important not to lose sight of how that value is transformed when they are grasped by real authors for real projects.

Kampa [24] explained that within the scope of location-based interactive storytelling authoring consists of several stages. Their own authoring process contained fifteen different tasks that were classified as creative, technical and scientific and for each task they recorded how much effort went into each task. Their results showed that most of the effort went into the creative tasks which consisted of things such as finding locations, taking pictures, producing videos, writing scripts, etc. They discuss that authoring locative digital interactive stories takes tremendous effort. Stefnisson et al. [8], refer to authoring as a "long and arduous process" and explain that in order to create interesting choices for the reader a large amount of content needs to be invested in a story. They argue that while researchers have previously addressed useful features for authoring tools, the creation of content remains a challenge.

To help develop a greater understanding of the authoring process and what steps it might entail we previously undertook a systematic literature review of the academic work around authoring tools [16] analysing papers across three decades: starting with the first ACM Hypertext conference proceedings publication in 1987 and the first ICIDS conference proceedings publication in 2001. From these papers we were able to elicit a set of authoring processes that have been mentioned in the literature, identifying seven distinct activities. Table 1 shows the results of that study. Note that although we have listed the steps in the order in which they are likely to occur, the analysis does not claim that all the steps are always present, or that they are undertaken in any strict order, to the contrary it seems likely that authors will have their own personalised approaches, and may iterate many times across different steps. 
In this paper we attempt to understand the authoring problem in terms of these steps, through qualitative interviews with a wide variety of interactive narrative authors.

\section{Methodology}

In order to understand the challenges faced by authors we undertook a series of semi-structured interviews with hypertext authors, including people working with narrative games. This qualitative approach allowed us to explore the issues from the author's perspective. The study was approved by the University ethics committee (study number: ERGO/FEPS/47296).

Our sample is an opportunistic one, but we wanted to represent people from the interactive fiction community, academic, and commercial game worlds. Interviewees were approached through online interactive fiction forums such as the Interactive Fiction Community5, Choice of Games6, Interactive Fiction on Reddit7 and Text Adventures8. Our approach to the online interactive fiction community had previously been shown to be effective by Short [25] who posted in several forums asking what interactive fiction tools were on authors' wish lists. Other interviewees were approached via email and in person during the 30th Hypertext and Social Media conference in Hof, Germany (2019) where many expert researchers mostly in hypertext fiction were present. In total we interviewed 20 people, 15 male and 5 female, with 12 (10 male, 2 female) coming broadly from the interactive fiction community, 5 ( 4 male, 1 female) from the academic community, and 3 ( 2 female, 1 male) from the game development community. As an opportunistic sample we ended up with a 3:1 ratio of male to females and this may have impacted the importance of statements on different stages.

We asked all the interviewees a structured set of questions categorised in three sections: Context, Process, and Issues and Effects, allowing open follow up questions and discussion where appropriate to clarify their answers. In the context section we asked people questions that were relevant to the tools they have used and their reasons behind wanting to engage with interactive storytelling. In the process section we asked them questions about the authoring process that they followed. In the issues and effects section we asked them questions that were relevant to any issues they have encountered and what effect those had on their overall writing process and stories.

Our protocol was to contact the interviewees prior to the interview to allow them to read the participant information sheet and sign a consent form. Each interview was then conducted, most by video conference, lasting around 30 minutes. Interviews were recorded, and the recording was then transcribed and coded. Codes were generated based on two areas of interest. The first set of codes reflected steps in the authoring process, this allowed us to validate the seven steps from [16] and explore whether authors referred to other steps not otherwise mentioned in the literature. The second set of codes were based on the issues that participants reported encountering while authoring. These codes were then grouped together in themes using an iterative process, and mapped to the steps in the authoring model.

\section{Results}

\subsection{The authoring process}

Table 1 briefly describes the seven interactive authoring steps we identified through our previous work. To be able to verify those steps, we asked the authors to tell us what steps they undertake as part of their authoring process. We were able to confirm that our authoring process model is compiled of steps that many authors are truly undertaking, and we extended that model with an addition of two more steps that were not reflected in the original systematic literature review, however are discussed in relevant literature as steps in media production by [26]. Table 2 shows the extended list of steps and the number of independent mentions they received from the authors.

\begin{tabular}{|c|c|}
\hline $\begin{array}{l}\text { Authoring } \\
\text { Activity }\end{array}$ & Explanation \\
\hline $\begin{array}{l}\text { Training / } \\
\text { Support }\end{array}$ & $\begin{array}{l}\text { Guiding the author on how to use the } \\
\text { authoring tool via examples, guides or } \\
\text { tutorials. }\end{array}$ \\
\hline Planning & $\begin{array}{l}\text { Sketching out the plot(s) of a story, creating } \\
\text { characters, drafting events, and making } \\
\text { notes. }\end{array}$ \\
\hline $\begin{array}{l}\text { Visualising / } \\
\text { Structuring }\end{array}$ & $\begin{array}{l}\text { Graphically creating, studying, and revising } \\
\text { the structure of a story (meaning the } \\
\text { relationships between events, characters, } \\
\text { chapters or scenes) and granting an } \\
\text { overview of the whole. }\end{array}$ \\
\hline Writing & $\begin{array}{l}\text { Inputting content that is part of the narrative } \\
\text { presented directly to the reader (typically } \\
\text { the text) rather than any specialised } \\
\text { language of the tool. }\end{array}$ \\
\hline Editing & $\begin{array}{l}\text { Revising, augmenting, and changing the } \\
\text { content and structure of the story, for } \\
\text { example embedding media in the text, } \\
\text { changing stylesheets, keeping a revision } \\
\text { record, or updating the structures or } \\
\text { relationships between nodes. }\end{array}$ \\
\hline $\begin{array}{l}\text { Compiling / } \\
\text { Testing }\end{array}$ & $\begin{array}{l}\text { Checking that the design is complete and } \\
\text { error free, for example without any loose } \\
\text { ends or empty nodes. Also, in the case of } \\
\text { using a tool with its own vocabulary that the } \\
\text { language was used without syntactical } \\
\text { errors or any other coding faults. }\end{array}$ \\
\hline
\end{tabular}

Table 1 - Systematic Literature Review Results [16]
5 https://intfiction.org/

6 https://forum.choiceofgames.com/
7 https://www.reddit.com/r/interactivefiction/

8 http://textadventures.co.uk/forum 


\section{Authoring activity}

\begin{tabular}{l|l} 
Ideation & 3 \\
Training \& Support & 8 \\
Planning & 17 \\
Visualising \& Structuring & 12 \\
Writing & 18 \\
Editing & 10 \\
Compiling \& Testing & 9 \\
Publishing & 1
\end{tabular}

Table 2 - List of authoring activities and number of independent mentions by interview participants

The additional steps we added are Ideation and Publishing:

Ideation we define as the stage of creative thinking, the birth of ideas and the coming together of story components to build the narrative foundation of a story.

"I mean the original idea was to do like a Rashomon type of thing. I didn't have the technology to pull it off quite." - P19

Publishing we define as the step of exporting a story format and making it available, or distributing it through a venue where readers will be able to access and read it.

"If you are trying to say how to sell my Twine game you probably need to learn how to leverage your publishing and polish resources and have a little bit of technical muscle before you are gonna be able to be successful with that." - P18

One of our structured questions targeted specifically the venues of publishing and therefore we heard opinions from most participants on that step of the process, but we only coded it for those who mentioned it specifically as a step in the authoring process.

Every step identified in our previous work was identified multiple times. Predominantly the planning, structuring, writing and editing steps, indicating that these are the areas of most focus for authors. In our previous work we also identified a cluster which we called Advanced Activities that was dependent on some of the specialist tools being described (for example, authoring guided tours). This was not present in our interviews, and shows the sampling bias between what researchers consider as important authoring steps, and the real-life experience of real authors using mainstream tools.

For the same reason, Ideation and Publishing were not steps that we discovered through the academic research, perhaps because for academics studying the field of digital interactive narratives, great importance falls on understanding narrative patterns, design patterns, models of interactivity, creating simple tools and simplifying authoring, all which sit somewhere in the middle steps of the authoring process. Ideation and Publishing are mostly the concern of authors who are wrestling with wider pragmatic questions: what should I write, how will people read it, and how will I get paid?

\subsection{Authoring Issues}

From the 20 participants (identified in the following as P1P20) we also gathered a list of 59 issues which we then classified under 18 unique codes. The codes were then grouped under 5 high level themes. Figure 1 shows the themes and codes, the number of unique participants that raised them, and gives an example quote from the interviews. The following look at each of these high-level themes.

\subsubsection{User / Tool Misalignment}

This theme covers those issues that relate to the misalignment between the expectations or expertise of the user and the capabilities and approach of the tool. The most common problem was a conceptual misalignment between what the authors wanted to achieve and what the tool could actually do. It would be unfair to describe this as missing functionality, as in some cases users were clearly attempting to do things that the tool was not designed for:

"Inform 7 is very physical where you have a layout you can move from room to room and it keeps track of you. I wanted that experience for people in Twine. And so I created a story where you can move from room to room and go back and from where you came but Twine was no good for that physicality." - P1

The one exception we made (to feature requests) was around interactive dialogue, which was frequently mentioned, especially in the common tools (Twine and Inform7).

Other types of misalignment included ontological misalignment, where the vocabulary and structures in the tool did not match the favoured mental model of the user; and workflow misalignment, where the tool required the author to work in an order that they were uncomfortable with.

\subsubsection{Documentation}

Documentation covers issues arising from a tool's tutorials and user manuals failing to describe properly how things work or failing to convey the full capabilities of the tool. Inspired by the Johari window [27] (made famous by Donald Rumsfeld) we codified issues in this category into the known unknowns (where authors knew what they wanted to do with a tool, were aware that the tool could do it, but could not figure out how to make it happen) and the unknown unknowns (where they did not know, and found it hard to discover, whether the tool had a particular capability or not).

"With Twine I run into a lot of issues where I wanted my game to look a little different and couldn't figure out how to make that happen." - P5 


\begin{tabular}{|c|c|c|c|c|}
\hline Theme & Code & Mentions & Participant & Quote \\
\hline \multirow{4}{*}{$\begin{array}{l}\text { USER/TOOL } \\
\text { MISALIGNMENT }\end{array}$} & $\begin{array}{l}\text { CONCEPTUAL } \\
\text { MISALIGNMENT }\end{array}$ & 10 & P11 & $\begin{array}{l}\text { I wanted to have a much more constructed programmed } \\
\text { occasions... I ended up coming up with a solution...definitely not } \\
\text { the way I originally envisioned it and that's because of the } \\
\text { constraints of Twine. }\end{array}$ \\
\hline & $\begin{array}{l}\text { EXPERTISE } \\
\text { MISALIGNMENT }\end{array}$ & 2 & P10 & $\begin{array}{l}\text { People came into it and even if they had a really good idea of what } \\
\text { they wanted to do with it, people were often very overwhelmed by } \\
\text { the amount of functionality .... that cause a lot of people a certain } \\
\text { amount of angst.... }\end{array}$ \\
\hline & $\begin{array}{l}\text { ONTOLOGICAL } \\
\text { MISALIGNMENT }\end{array}$ & 2 & P14 & $\begin{array}{l}\text { It's made me think way more about simple things } \ldots \text { and to } \\
\text { deconstruct common objects that I think everybody has a pretty } \\
\text { comprehensive mental image of in order to make them work in the } \\
\text { tool. }\end{array}$ \\
\hline & $\begin{array}{l}\text { WORKFLOW } \\
\text { MISALIGNMENT }\end{array}$ & 1 & P1 & $\begin{array}{l}\text { [With Inform7] I could be a player and see aw this is missing this } \\
\text { there is obviously an error. But with Twine and CS I couldn't } \\
\text { really play the whole game until I finished it and by then I had less } \\
\text { motivation to go back and fix things. }\end{array}$ \\
\hline \multirow{2}{*}{ DOCUMENTATION } & $\begin{array}{l}\text { THE KNOWN } \\
\text { UNKNOWNS }\end{array}$ & 7 & P5 & $\begin{array}{l}\text { With Twine there seem to be a couple of options; you either use a } \\
\text { CSS on top of an exciting story template and I couldn't find good } \\
\text { documentation for that or you could write your own story format } \\
\text { which there is almost no documentation for it. }\end{array}$ \\
\hline & $\begin{array}{l}\text { THE UNKNOWN } \\
\text { UNKNOWNS }\end{array}$ & 2 & P11 & $\begin{array}{l}\text { There are things that I found myself saying I'd really kind of like } \\
\text { to do something like this but I am not sure I know how to do it or I } \\
\text { am not sure it's worth the effort. Those are problematic. }\end{array}$ \\
\hline \multirow{4}{*}{ COMPLEXITY } & $\begin{array}{l}\text { VARIABLE } \\
\text { TRACKING }\end{array}$ & 3 & P13 & $\begin{array}{l}\text { [In Twine] all of the variables that you are referencing exist in } \\
\text { some way and it's hard to track variables across nodes. }\end{array}$ \\
\hline & SCALABILITY & 3 & P4 & $\begin{array}{l}\text { Definitely some of the chapters probably got a bit too complicated } \\
\text { so actually testing them and getting them to work was a bit } \\
\text { difficult. }\end{array}$ \\
\hline & VERSIONING & 2 & P18 & $\begin{array}{l}\text { Like it doesn't have any version control at all which is horrible. } \\
\text { You can lose a lot of work immediately... it's really tough to do } \\
\text { different versions. }\end{array}$ \\
\hline & $\begin{array}{l}\text { CONTENT } \\
\text { TRACKING }\end{array}$ & 1 & P7 & $\begin{array}{l}\text { I wrote a } 3000 \text { word } 30 \text { lexia scene in one day and then got to the } \\
\text { end of it and realised that I'd called one character Brianna and I } \\
\text { didn't mean Brianna ... keeping track of the cast was tricky. }\end{array}$ \\
\hline \multirow{3}{*}{$\begin{array}{l}\text { PROGRAMMING } \\
\text { ENVIRONMENT }\end{array}$} & $\begin{array}{l}\text { LACK OF } \\
\text { PROGRAMMABLE } \\
\text { ENVIRONMENT }\end{array}$ & 4 & P11 & $\begin{array}{l}\text { It seems like the tools that we have now are a little bit more } \\
\text { fragmented in the sense that you have to step out of the tool to do } \\
\text { scripting... where we had a unified environment, now you have to } \\
\text { have several tools. }\end{array}$ \\
\hline & $\begin{array}{l}\text { SEPARATION OF } \\
\text { CONTENT AND } \\
\text { BEHAVIOUR }\end{array}$ & 3 & P8 & $\begin{array}{l}\text { In terms of proof reading and editing Inform } 7 \text { all of your pros, } \\
\text { English language sits together with the programming code and so } \\
\text { in terms of typos that's actually quite hard. }\end{array}$ \\
\hline & $\begin{array}{l}\text { LACK OF } \\
\text { DEBUGGING } \\
\text { TOOLS (TESTING) }\end{array}$ & 2 & P1 & $\begin{array}{l}\text { The one thing that Twine doesn't have is good tools that check if } \\
\text { there are problems with your code. The only thing it has is that it } \\
\text { tells you if it has dead links that don't go anywhere. }\end{array}$ \\
\hline \multirow{5}{*}{ LIFECYCLE } & PROFITABILITY & 2 & $\mathbf{P 3}$ & $\begin{array}{l}\text { The challenge seems to be getting any money out of it because for } \\
\text { most of these I am not selling them and while each would let me } \\
\text { do that quite easily I don't know how many people would actually } \\
\text { pay for it. }\end{array}$ \\
\hline & $\begin{array}{l}\text { PLATFORM } \\
\text { SUPPORT }\end{array}$ & 1 & $\mathbf{P 3}$ & $\begin{array}{l}\text { One of the biggest problems I have is that running the stories in a } \\
\text { web browser often limits kind of how well it work. }\end{array}$ \\
\hline & MAINTENANCE & 1 & P5 & $\begin{array}{l}\text { With Desmos you write all of your interactive activities and then } \\
\text { you get a single class code that you give out that opens up a link } \\
\text { and takes duty. That works for the initial publication but then I } \\
\text { discovered that there is no way to update the game after you } \\
\text { release it. }\end{array}$ \\
\hline & CURATION & 1 & P11 & $\begin{array}{l}\text { Curation is a second level concern, it's not just does the tool help } \\
\text { you get there it's also the mechanisms of curation that are going to } \\
\text { help writers get found and get exposure... }\end{array}$ \\
\hline & DISTRIBUTION & 1 & P8 & $\begin{array}{l}\text { Once you put the files on there sometimes it's a bit difficult for the } \\
\text { end user to get them ... sadly people are becoming totally adverse } \\
\text { to doing other work other than clicking on a link and getting the } \\
\text { game to play.... }\end{array}$ \\
\hline
\end{tabular}

Figure 1 - List of codes and themes with associated quotes from participants relevant to the codes and the number of times each code was mentioned 


\subsubsection{Complexity}

Complexity describes the technical issues that make it challenging for content to be created consistently or for the story to be developed coherently as the story is written. Examples we identified are content tracking, which refers to the internal consistency of the text, and variable tracking, which refers to the external consistency of the state machine around the text:

"It's hard to keep track of all the variables floating around and all the possible combinations of those variables and so because of that sometimes I'll forget one thing. I'll play through one thing and I'll realise there is an entire chunk of text missing so I tried to list the case but there are so many cases." - P1

As the story grows these seem to compound into a general problem of scalability where the sheer size of the text (and any behaviour specifications) simply become overwhelming. A final issue is versioning the inability to maintain working versions of a story as it develops, and guard against any potential loss of work.

\subsubsection{Programming Environment}

The programming environment is the part of the authoring tool where authors can define behaviour, sometimes independently, and sometimes directly alongside the content of the story. In cases where it was done together this sometimes caused complaints about a lack of separation of content and behaviour which complicates editing and testing when things such as spelling errors and machine language errors are not differentiated.

"If you are not using Harlowe 9 and you don't have autocomplete it's very difficult to see what's code and what's not and it's tough to separate the writing from the functionality and see it very clearly at a glance." - P18

Other issues included the lack of debugging tools that clearly state what a programmable error may be when a story doesn't compile, and in some cases the lack of a programmable environment which for some is very restricting in terms of what they can do with a tool.

\subsubsection{Lifecycle}

Our last theme relates to those issues that describe the overall lifecycle of a digital interactive story. A number of authors mentioned the lack of venues for distribution, and a resulting problem with profitability from their work, as well as a lack of spaces that could provide curation for all these works for longevity and accessibility.
"I feel bad when something feels like they have a cool Twine game and then think but how do I sell it? Push button publishing for people is something people really want." - P18

On the same topic we noted maintenance as the difficulty of making updates to a story after publication. Finally, we defined platform support as issues related to publishing platforms not being able to fully support the functionality of a story (for example, compatibility issues with web browsers), which means some effects are likely to be lost from the reading experience.

\section{Analysis}

These author interviews provide a picture of the authoring process that overlaps significantly with our previous review of the literature, but does reveal that authors see an extended process, that starts before many tools are involved, and continues into a publishing phase. The authoring challenges are many, and spread across the various authoring stages.

The most significant issue, reported by the most authors, was that they suffer from a misalignment between their own expectations and the tool they are using, mostly because they either don't know how to approach the tool or because they have approached the wrong tool. Documentation seems to be inadequate for helping them to discover how to realise their vision, or too slow to communicate that what they want to achieve is not possible.

As might be expected the complexity of managing both a story and a machine to execute behaviour is considerable. When tools contain a programming environment they can be perceived as too complicated by people who want to do programmable things in a simple way because they lack programming skills, or perceived as too simple by people who want to do more complex things than what the tool may offer. This seems like a fundamental tension. Responsibility falls both on authoring tools that lack the flexibility in providing certain authoring features and on authors who are not researching well enough which tool they should use for a given project. When your authoring tool is a hammer, every story looks like a nail.

Yet, those who manage to overcome any misalignment and prepare their story, are faced with the crucial step of sharing their creation. As it stands today, the venues for publishing interactive stories are limited to a handful of online repositories which host, but do not promise much in terms of maintenance and profitability.

Having identified these authoring challenges in Section 4.2 it is possible to now map them against the extended set of authoring processes we identified in Section 4.1. Figure 2 shows a summary of issues mentioned by participants, represented by the codes we identified, and mapped to the step of the authoring process those issues occurred. The majority of issues lie within the writing step most of them occurring because of conceptual misalignment. 


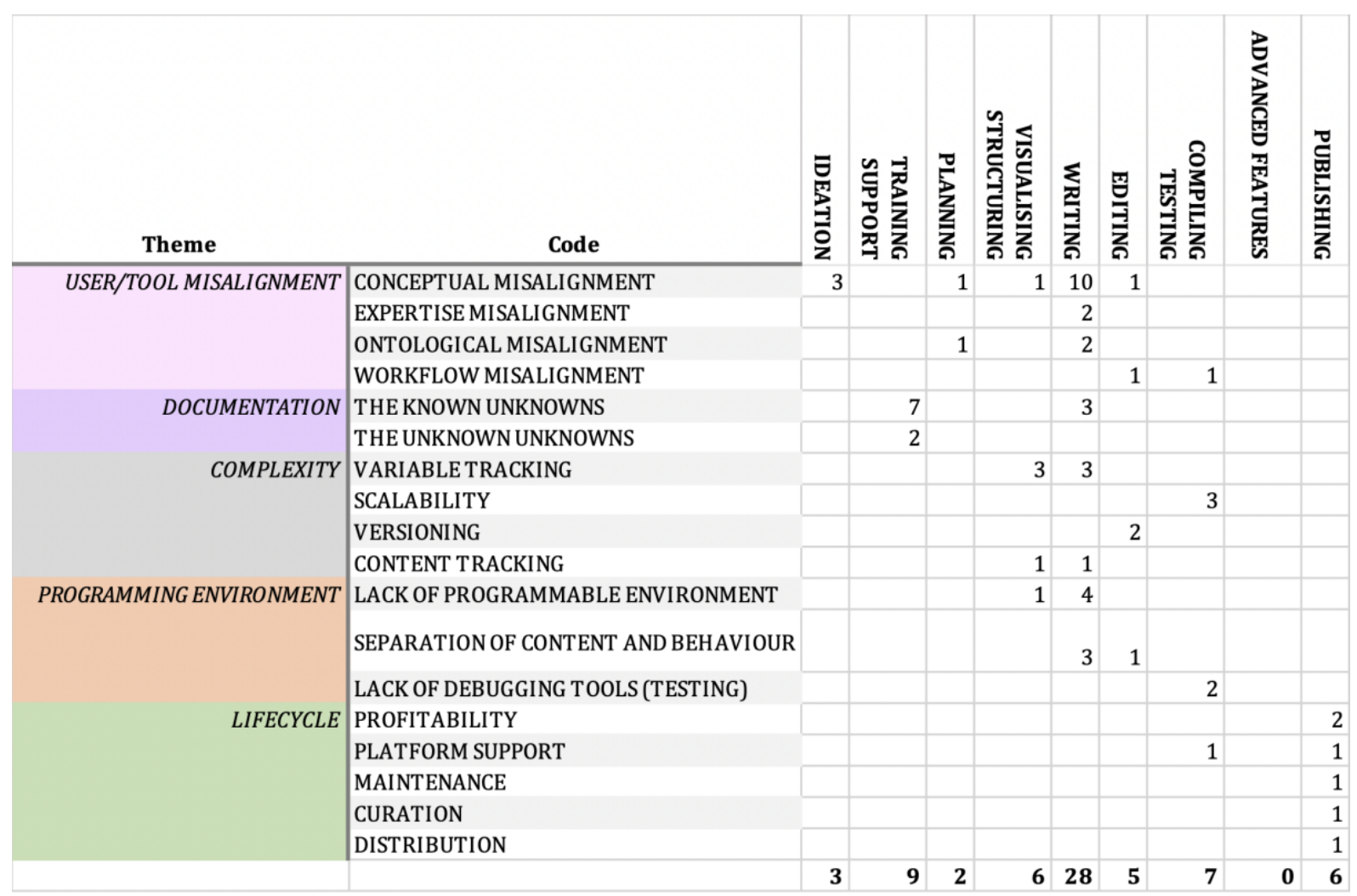

Figure 2 - List of codes and themes according to issues mentioned by interviewees

By looking at how the numbers are distributed on the table we can make out approximate phases of authoring, and the common issues that occur within those phases. For example, in the first phases of the process (which we might call preproduction, from ideation to planning) the main issues are due to misalignment and problems with documentation. Then in the middle phase (production, from visualising to editing) we see that while many of these previous issues persist they are joined by a number of additional issues that have to do with the complexity and the programming environment of a tool. In the final phase (post-production, from testing to publishing) we see only a few of the previous issues persisting and we get a final set of issues that are almost exclusively related to publishing.

This makes intuitive sense, as it is in the pre-production process where a lot of preparing and planning is undertaken. This continues into production where they manifest as issues with the generation of content in terms of writing, editing and some testing, and are joined by a set of other more technical issues as programming may become necessary. At the end, an entirely new set of issues arises as final testing and publishing commence. Thus, we see a gradual progression of different issues emerging and then fading as the author moves through the different steps and phases of production. Tool designers should therefore consider which parts of the authoring process they are targeting (likely to fall into one of more of pre, production, and post) and look to address the specific issues that arise within those stages, as well as attempting sensible import or export facilities to tools that come before or after their own in the process.

\section{Conclusion}

In this paper we have presented our findings from a series of 20 interviews we conducted with a number of digital interactive authors about the authoring process. From the data gathered we were able to extend our previous work with regards to the definition of an authoring process for digital interactive narratives. In addition, by collating the information gathered from the interviewees we were able to identify 18 specific authoring challenges across five themes: User/Tool Misalignment, Documentation, Complexity, Programming Environment, and Lifecycle. We were also able to match those issues against the updated authoring process, mapping them to the relevant step in that process, acting as both an additional validation of the processes we have identified, and also as a valuable analysis in its own right that could help authoring tool designers to focus their tools on specific phases of production, and to address the specific problems found there by authors.

The two additional authoring steps we identified were Ideation and Publishing, missed previously because they are not typically the concern of researchers (and our model was based on a literature review), butare important to authors who wish to make a living from their creative efforts. The mapping of issues 
to steps reveals three phases, with some overlap: preproduction, production, and post-production.

The issues mentioned in the pre-production phase are arguably the most problematic and most difficult to address. This is because they are mostly concerned with the misalignment of authors and tools, which is both an educational and a technical challenge. It is possible to create powerful self-teaching tools, a recent example would be the PS4 game and platform Dreams 10 meant to enable anyone to create their own complex games and digital stories, but the balance between complexity and expressive power will not simply go away, and seems a fundamental tension for interactive story authoring.

The production phase is the one most relevant to tool designers as those issues are mainly concerned with the difficulty of using the system and also the relationship between author and the programming environment. A key design challenge is clearly to help authors manage the complexity of their stories, but while there are examples of systems doing this for behaviour (using patterns, natural language, or graphics) it is less common to see the internal complexity of the story managed, or linked successfully to that behaviour.

Finally, the post production phase is one that is associated with the whole social and technical infrastructure of finding, buying, and reading stories. Itch.io 11 is a website that currently allows authors to self-publish and advertise their work and Choice of Games LLC12 is one of the most popular publishers of text based interactive stories that maintains their own tool and associated publishing pipeline. But they do not benefit from the same mass awareness and coverage as similar initiatives for games (such as Steam or the Play or App Stores).

Many authoring tool developers pursue technical solutions to the authoring problem, exploring new interfaces or abilities that they hope will strike a chord with authors, and encourage them to experiment more deeply with what the technology can do. In other words, the assumption is that authoring issues are a result of the restrictive nature of the tools, their opacity, and their lack of appropriate features. Our findings reveal a more complex picture, in terms of the fundamental tensions between expressivity and complexity, the author's mental model and the tool's data model, and the stages of the process it is used for verses the ones it was designed for.

Murray [2] tells us that we need storytelling because stories are what maintain our history, shape our culture, and protect our traditions. It is also a form of entertainment that everyone engages with at some level. Digital interactive storytelling is a relatively new form of storytelling. It is already embedded in narrative games, a successful industry, and recently has found a wide new audience through television $[28,29]$. But the authoring problem is real, discouraging authors from exploring the power of the medium, and acting as a barrier to new voices and types of work. Our work aims to shed light on the authoring process itself, to break down the monolithic view of authoring, and help tool creators design more focused tools with an awareness of the challenges ahead.

\section{ACKNOWLEDGMENTS}

We would like to offer our sincere gratitude to those authors who have agreed to speak with us and share their experience. Without them, and their openness about their craft, we wouldn't have been able to conduct this research.

\section{REFERENCES}

[1] R. McKee, Story. USA: Methuen, 1998.

[2] J. H. Murray, Hamlet on the Holodeck: The Future of Narrative in Cyberspace, Updated. Cambridge, Massachusetts: The MIT Press, 2017.

[3] J.Pope, 'How do readers interact with hypertext fiction? An empirical study of readers' reactions to interactive narratives.', phd, Bournemouth University, Fern Barrow, Poole, Dorset, BH12 5BB, UK, 2007.

[4] M. O. Riedl, 'Incorporating Authorial Intent into Generative Narrative Systems', in Intelligent Narrative Technologies, 2009, p. 4

[5] D. E. Millard, C. Hargood, Y. Howard, and H. Packer, "The StoryPlaces Authoring Tool: Pattern centric authoring', in Authoring for Interactive Storytelling 2017, Nov. 2017, Accessed: Jun. 24, 2018. [Online]. Available: https://eprints.soton.ac.uk/416037/.

[6] H. Koenitz and K.-J. Chen, 'Genres, Structures and Strategies in Interactive Digital Narratives - Analyzing a Body of Works Created in ASAPS', in Interactive Storytelling, 2012, pp. 84-95.

[7] M. Kriegel, R. Aylett, J. Dias, and A. Paiva, 'An Authoring Tool for an Emergent Narrative Storytelling System', in Intelligent Narrative Technologies, California, 2007, p. 8.

[8] I. S. Stefnisson and D. Thue, 'Authoring Tools should be Mixed-initiative Systems', in Authoring for Interactive Storytelling, 2017, p. 4.

[9] E. Short, 'Writing in Collaboration with the System', Emily Short's Interactive Storytelling, Oct. 29, 2014. https://emshort.blog/2014/10/29/writing-incollaboration-with-the-system/ (accessed Jan. 21, 2019).

[10] U. Spierling and N. Szilas, 'Authoring Issues beyond Tools', in Interactive Storytelling, 2009, pp. 50-61.

[11] F. G. Halasz, 'Reflections on NoteCards: Seven Issues for the Next Generation of Hypermedia Systems', in Proceedings of the ACM Conference on Hypertext, New York, NY, USA, 1987, pp. 345-365, doi: 10.1145/317426.317451.

[12] N. Szilas, U. Richle, and J. E. Dumas, 'Structural Writing, a Design Principle for Interactive Drama', in Interactive Storytelling, 2012, pp. 72-83.

[13] A. Nakasone and M. Ishizuka, 'SRST: A Storytelling Model Using Rhetorical Relations', in Technologies for Interactive Digital Storytelling and Entertainment, 2006, pp. 127-138.

[14] J. G. K. Foss and A. I. Cristea, "The Next Generation Authoring Adaptive Hypermedia: Using and Evaluating the MOT3.0 and PEAL Tools', in Proceedings of the 21st ACM Conference on Hypertext and Hypermedia, New York, NY, USA, 2010, pp. 83-92, doi: 10.1145/1810617.1810633.

[15] R. Aylett, S. Louchart, and A. Weallans, 'Research in Interactive Drama Environments, Role-Play and Story-Telling', in Interactive Storytelling, 2011, pp. 1-12.

[16] S. Kitromili, J. Jordan, and D. E. Millard, 'What is Hypertext Authoring?', in Proceedings of the 30th ACM Conference on Hypertext and Social Media, Hof, Germany, Sep. 2019, pp.55-59, doi: 10.1145/3342220.3343653.

[17] D. Webster and M. A. Hopkins, Consider the Consequences. USA: The Century Company, 1930.

[18] 'History of CYOA', Chooseco LLC. https://www.cyoa.com/pages/history-ofcyoa (accessed Mar. 26, 2019).

[19] N. Montfort, Twisty Little Passages. USA: The MIT Press, 2005.

[20] J. D. Bolter and M. Joyce, 'Hypertext and Creative Writing', in Proceedings of the ACM Conference on Hypertext, NY, USA, 1987, pp. 41-50, doi: $10.1145 / 317426.317431$.

[21] E. J. Aarseth, Cybertext Perspectives on Ergodic Literature. United States of America: The John Hopkins University Press, 1997. 
[22] Y. Shibolet, N. Knoller, and H. Koenitz, 'A Framework for Classifying and Describing Authoring Tools for Interactive Digital Narrative', 2018, pp. 523-533.

[23] U. Spierling, "Tools and Principles for Creation in Interactive Storytelling The Issue of Evaluation', in Authoring for Interactive Storytelling, 2018, p. 6.

[24] A. Kampa, 'Authoring Tools: Saving Effort in the Authoring Process for Interactive Digital Storytelling Experiences', in Authoring for Interactive Storytelling, 2018, p. 6.

[25] E. Short, 'What people said about the Missing Tools (and some that aren't missing at all)', Emily Short's Interactive Storytelling, Mar. 29, 2014 https://emshort.blog/2014/03/29/what-people-said-about-the-missingtools-and-some-that-arent-missing-at-all/ (accessed Jan. 21, 2019).
[26] L. Hardman, Ž. Obrenović, F. Nack, B. Kerhervé, and K. Piersol, 'Canonical Processes of Semantically Annotated Media Production', Multimedia Syst, vol. 14, no. 6, pp. 327-340, Dec. 2008, doi: 10.1007/s00530-008-0134-0.

[27] J. Luft and I. Harrignton, 'The Johari window, a graphic model of interpersonal awareness.', in Proceedings of the western training laboratory in group development., Los Angeles, 1955.

[28] C. Roth and H. Koenitz, 'Bandersnatch, Yea or Nay? Reception and User Experience of an Interactive Digital Narrative Video', in Proceedings of the 2019 ACM International Conference on Interactive Experiences for TV and Online Video, Salford (Manchester), United Kingdom, Jun. 2019, pp. 247254, doi: $10.1145 / 3317697.3325124$.

[29] L. Kolhoff and F. Nack, 'How Relevant Is Your Choice?', in Interactive Storytelling, Cham, 2019, pp. 73-85, doi: 10.1007/978-3-030-33894-7_9. 